\title{
EL NACIONAL LIBERALISMO DEL ECONOMISTA PERUANO JOSÉ MANUEL RODRÍGUEZ, 1857-1936*
}

\author{
NATIONAL LIBERALISM OF THE PERUVIAN \\ ECONOMIST JOSÉ MANUEL RODRÍGUEZ, 1857-1936
}

\author{
Carlos Contreras Carranza \\ Pontificia Universidad Católica del Perú, Lima, Perú, ccontre@pucp.edu.pe
}

Resumen. El artículo busca contribuir a la reconstrucción del pensamiento económico latinoamericano, tan necesitado de una tradición propia en esta materia. José M. Rodríguez fue un economista peruano cuyo trabajo discurrió entre las últimas décadas del siglo XIX y las primeras del Xx. Fue funcionario público y escribió profusamente sobre la economía peruana de la época, proponiendo diagnósticos y soluciones a sus problemas. Identificó los defectos crónicos de la economía nacional y desarrolló ideas que, partiendo del liberalismo, evolucionaron hacia una doctrina que bautizamos como nacional-liberalismo, por su semejanza en algunos puntos con el nacional-socialismo europeo. Rodríguez propuso la protección de la industria nacional y el control de la inversión extranjera, apartándose de un liberalismo económico ortodoxo y simple.

Palabras clave: pensamiento económico; liberalismo; nacionalismo económico.

Abstract. This article seeks to contribute to the reconstruction of Latin American economic thought, much in need of its own tradition in this matter. José M. Rodríguez was a Peruvian economist whose work ran between the last decades of the nineteenth century and the first decades of the twentieth century. He was a public official and wrote profusely about the Peruvian economy of that time, proposing diagnostics and solutions to its problems. He identified the chronic defects of the national economy and developed ideas that, based on liberalism, evolved into a doctrine baptized as European national-liberalism. Rodríguez proposed the protection of the national industry and the control of foreign investment, differentiating itself from an orthodox and simple economic liberalism.

Key words: Economic thought; liberalism; economic nationalism.

Fecha de recepción: 29 de agosto de 2014. Fecha de aceptación: 29 de abril de 2015.

* Una versión preliminar de este texto fue presentada en las XIV Jornadas Interescuelas de los Departamentos de Historia, en Mendoza, Argentina, del 2 al 5 de octubre de 2013. Agradezco la acogida de Juan Odisio y Paola Chenillo, coordinadores de la mesa donde se presentó la ponencia, y los comentarios recibidos en esa ocasión por parte de Jimena Caravaca. Estoy asimismo en deuda con los comentaristas anónimos de la revista América Latina en la Historia Económica, que tuvieron la gentileza de enviar sus comentarios a una versión anterior del artículo.

Am. Lat. Hist. Econ., año 23, núm. 1, enero-abril, 2016, pp. 41-67 


\section{INTRODUCCIÓN}

$\mathrm{E}$ ste artículo presenta la trayectoria intelectual y política de José Manuel Rodríguez (1857-1936), economista peruano, cuya actividad discurrió entre las postrimerías del siglo XIX y el primer tercio del $\mathrm{XX}$. Sus trabajos estuvieron hondamente marcados por el fracaso de la era del guano, entre 1845 y 1880, y la derrota de Perú en la guerra del salitre (1879-1883). El lapso de vida intelectualmente activa de Rodríguez coincidió con la necesidad de reconstruir sobre nuevas bases la economía pública de la nación, así como de renovar su aparato exportador, casi totalmente desmantelado tras la Paz de Ancón en 1883. Tuvo una existencia lo bastante larga como para poder ser testigo de logros importantes en ambos procesos durante las primeras tres décadas del siglo $\mathrm{XX}$, y pudo observar también su serio deterioro con el estallido de la gran depresión de la economía mundial en los años treinta.

Haber vivido el fracaso de la era del guano y la inestabilidad o precariedad de la bonanza exportadora del siguiente periodo, provocaron en su pensamiento una extraña combinación entre un liberalismo clásico, asentado en la lectura de los grandes economistas europeos del siglo XIX, y un nacionalismo económico que, desde mediados de la década de 1920 pareció inspirado en la política de las naciones industrializadas tardíamente, como Italia, Alemania y Japón.

El objetivo del artículo es contribuir a la reconstrucción del pensamiento económico latinoamericano y peruano en particular, un país de cuyo pensamiento económico moderno se conoce muy poco, más allá del socialismo indigenista de José Carlos Mariátegui o el antiimperialismo táctico de Víctor Raúl Haya de la Torre. ${ }^{1}$

Las ideas económicas latinoamericanas, especialmente aquellas anteriores a la segunda guerra mundial, no recibieron hasta hace poco mucha atención por considerarse que fueron sólo una réplica del pensamiento europeo y que, en consecuencia, poco de original podría encontrarse en ellas. Sin embargo, esta postura ha ido cambiando en la medida que la investigación se ha acercado a las fuentes de dicho pensamiento, como los libros, folletos y revistas que inspiraron los trabajos de Jacobsen (2002, 2007) y Gootenberg (2002). Aun cuando el pensamiento europeo efectivamente influyó en las ideas económicas latinoamericanas, los pensadores locales hicieron un esfuerzo interesante de adaptación de los paradigmas

\footnotetext{
${ }^{1}$ Existe un libro, poco conocido, de César Augusto Reinaga (1969), Esbozo de una historia del pensamiento económico en el Perú, que rescata a varios personajes de las épocas colonial y republicana. Más reciente y difundido es el libro de Paul Gootenberg (1998) que cubre el periodo 1821-1883.
} 
importados a la realidad de sus países, que después de su independencia de España habían enfrentado agudas situaciones de crisis económica y política, sin contar con un Estado pertrechado de instrumentos y personal capaz de intervenciones enérgicas y adecuadas. A partir de finales del siglo XIX ellos se propusieron no solamente el diseño de políticas que trajeran fuertes dosis de progreso y modernización que acortasen la brecha con las naciones del hemisferio norte, sino que además construyesen una economía pública suficiente y estable que, a la vez, en el caso de países de densa población indígena como Perú, permitiese la integración de estos segmentos demográficos secularmente marginados de la vida urbana moderna. No era sencillo dar con un modelo que satisficiese tantos requerimientos, lo que forzó a los economistas latinoamericanos a repensar las teorías importadas de otros lugares.

\section{EL FUNDADOR DE LA ECONOMÍA PERUANA}

José Manuel Rodríguez, cuyos primeros trabajos aparecieron en la década de 1880, fue uno de los primeros economistas peruanos. Por la envergadura de su labor, podría ser considerado el fundador de la disciplina en Perú. Rodríguez (1887, 1894, 1895, 1905 y en coautoría con Dancuart, 19021926) publicó obras centradas en temas económicos en las que, aparte de enfrentar los temas de debate de la economía peruana de su tiempo como el problema del billete fiscal, el reemplazo de los ingresos fiscales perdidos tras la guerra del salitre o la política de tarifas de aduana más conveniente para los intereses nacionales, se preocupó por difundir las ideas de la economía política trazada por los autores del clasicismo europeo, desde Smith y Say, hasta Jevons y Menger; ${ }^{2}$ además fundó la revista El Economista Peruano, que probablemente no sólo sea la publicación especializada en economía más antigua de Perú, sino una de las más constantes, puesto que perduró con muy pocas interrupciones por más de 30 años, entre 1909 y 1940. Militó políticamente en el Partido Constitucional, una agrupación que alcanzó a tener importancia en Perú desde 1885 hasta 1920 y cuya cabeza visible era Andrés Cáceres, un héroe sobreviviente de la guerra del salitre. Desde los últimos años del siglo XIX se convirtió en su ideólogo económico principal, representándolo en el Congreso o en los debates ocurridos en la prensa.

\footnotetext{
${ }^{2}$ Acerca de Smith y Say, véase Rodríguez (1895, pp. 12 y ss. y 28 y ss. y en general toda la primera parte). La difusión de las ideas de Jevons y Menger ocurrió más tarde, desde las páginas de la revista El Economista Peruano, donde reseñó y comentó sus ideas acerca del origen del valor, y en el caso de Menger destacó su estudio sobre la distribución del gasto por parte de las familias.
} 
La obra y la biografía de Rodríguez son prácticamente desconocidas; en los diccionarios biográficos más importantes del país no figura su nombre (Milla, 2004; Tauro, 1966), ni tampoco aparece información precisa sobre él en bases de datos y los motores de búsqueda de internet. ${ }^{3}$ En la compilación El pensamiento económico latinoamericano (Roque et al., 1945), Emilio Romero, redactor dedicado al capítulo de Perú, no menciona a Rodríguez; en cambio, Reinaga (1969) sí lo rescata en su Esbozo de una historia del pensamiento económico en el Perú, donde lo califica de "honra y prez del pensamiento económico peruano [...] a la altura de sus contemporáneos europeos" (p. 80). Incluso, varios de sus trabajos son inhallables hasta el momento, tales son los casos de El nuevo sistema o reforma tributaria aplicable al mundo (1905), sobre un nuevo modelo tributario, y el folleto "Supresión del impuesto" de 1920.

Los escasos datos que hemos podido conseguir nos dicen que nació en un pequeño pueblo de la sierra norte peruana un día indeterminado de 1857, y murió en Lima el 28 de septiembre de 1936, a los 78 o 79 años de edad. Nació en el distrito de Lucma, que por entonces pertenecía a la provincia de Otuzco, en la sierra del departamento de La Libertad. ${ }^{4} \mathrm{Se}$ desconoce quiénes fueron sus padres. Rodríguez, que escribió miles de páginas a lo largo de su vida, nunca hizo sobre ellos la menor alusión ni utilizó su apellido materno. Por el medio en que nació, se presume que debieron ser agricultores y que ellos mismos, o algún allegado de la familia, debieron contar con algunas posibilidades económicas, puesto que, una vez terminado el colegio, llegaron a mandar a nuestro personaje a estudiar a Trujillo, la ciudad más importante de la región.

Pero Rodríguez parece haber sido un economista autodidacta. Nunca presumió de tener un título académico o profesional, ni parece haber completado estudios en ninguna universidad o haber enseñado en alguna. Él mismo se presentaba, o era presentado, como "financista" o "publicista". La especialidad de economía en la universidad peruana no fue creada hasta la década de 1920, de modo que recién alrededor de 1930 egresaron de las aulas de la Universidad de San Marcos los primeros economistas peruanos con ese título. Pero ya desde 1875, con la creación de la Facultad de Ciencias Políticas y Administrativas en dicha universidad, comenzaron a dictarse en ella cursos de economía política, inicialmente a cargo del profesor francés Paul Pradier-Foderé, quien llegó a Perú precisamente para hacerse cargo de la nueva facultad.

\footnotetext{
${ }^{3}$ Salvo cuando se colocan valores específicos, en cuyo caso el buscador te puede remitir a una biblioteca o a la bibliografía de algún artículo sobre la historia económica del Perú.

${ }^{4}$ Actualmente Lucma pertenece a la provincia de Gran Chimú, cuya capital es Cascas.
} 
Cuando arribó a Lima, en diciembre de 1885, Rodríguez pudiera haber tomado clases en San Marcos como alumno libre. ${ }^{5}$ Únicamente sabemos que realizó estudios superiores en el Seminario de Trujillo; probablemente porque tentó ser sacerdote. El hecho es que entre 1882 y 1883 se instaló en el puerto de Pacasmayo, cuya actividad se había reanimado en la segunda mitad del siglo XIX a raíz de la agricultura del azúcar en los valles de la costa norte. Ahí, con 25 años de edad, dio muestras de la vocación editorial que lo acompañaría toda la vida, al dirigir (y al parecer fundar) el diario El Deber. Eran los momentos de la ocupación chilena, que había puesto en tensión a la opinión pública del país. ${ }^{6}$

Perú se hallaba dividido en diversos bandos que, al comando de distintos caudillos, proponían diferentes soluciones al problema de la guerra y la ocupación chilena. Rodríguez se enroló en el partido del coronel Andrés Cáceres, cuya postura era no aceptar una paz con cesión territorial, proponiéndose prolongar la guerra contra el invasor a través de una estrategia de resistencia basada en las guerrillas. En el norte, el coronel Miguel Iglesias hacía, en cambio, un llamamiento a favor de pactar un acuerdo de paz con Chile, aun si este implicase pérdidas territoriales, y conseguir así una desocupación rápida del país. Rodríguez fue un raro caso de hombre del norte que apoyó la causa de Cáceres, un hacendado de Ayacucho cuyas bases sociales se encontraban sobre todo en el sur y centro del país.

Apoyado por el ejército chileno, Iglesias fue quien tomó el control del Estado y firmó un acuerdo de paz con Chile en octubre de 1883. Una vez que el ejército chileno se retiró de Perú, el gobierno de Iglesias fue combatido por los caceristas hasta provocar su renuncia en diciembre de 1885 . El nuevo presidente fue Cáceres, naturalmente. Bendecido por la fortuna de haber militado en el bando triunfador, Rodríguez inició, bajo el gobierno de Cáceres, una carrera burocrática como oficial de presupuesto en la Cámara de Diputados del Congreso de la República. Publicó entonces su primer folleto de tema económico: La conversión del billete fiscal (1887). En esta primera publicación exhibió el método que practicaría toda su vida: empezar con una reconstrucción histórica del asunto a tratar, explicar la lógica detrás de las acciones de los agentes involucrados en él, describir las consecuencias que se seguían de ellas y terminar con una propuesta de

\footnotetext{
${ }^{5}$ Pradier-Foderé salió de Perú en 1879 durante la guerra del salitre, y murió en Francia en 1904 (Arrambide, 2013). Lo más probable es que debió haberlo hecho inmediatamente después o durante la guerra, puesto que las condiciones económicas en que fue contratado en Perú debieron seguramente empeorar tras el estallido de esta. Esto disminuye la probabilidad de que José Rodríguez haya tomado cursos con él. Pradier-Foderé publicó su curso en San Marcos en 1876 (Pradier-Foderé, 1876).

${ }^{6}$ Eduardo Rávago (28 de octubre de 1936 -a un mes de la muerte de Rodríguez-) y una pequeña nota en Benvenutto (1923) son las únicas fuentes de datos biográficos sobre Rodríguez.
} 
política. Al comenzar como una emisión de bancos particulares, los billetes fueron luego estatizados en una operación que dejó como beneficiarios tanto a los banqueros, que se deshicieron de un compromiso cuantioso, como al gobierno, que recibió ingresos extras (Morón, 1993). Los decretos de inconvertibilidad de los billetes emitidos a partir de 1875 abrieron una brecha creciente entre la estimación de la moneda de plata y la de papel, que naturalmente fue aprovechada por los hombres de negocios para pagar sus contribuciones al gobierno con la moneda mala y no con la buena.

En 1879, estallada la guerra del salitre, el propio gobierno, ante la quiebra de casi todos los bancos, continuó con la emisión de billetes como medio de resolver el déficit fiscal. Se trataba de la primera experiencia de moneda de papel en el país, acostumbrado desde el siglo XVI a la moneda metálica. La derrota en la guerra y su rechazo por el ejército invasor volvió al billete fiscal una moneda envilecida. Cuando se retiró el ejército de Chile, la población esperaba que el padre de la criatura, que era el Estado, la reconozca y le dé el soplo de vida que aliviaría a tantas personas, pero eso no sucedió. El repudio del billete, que fue la política asumida, mereció la censura de Rodríguez, por significar para él una burla a la confianza pública y la evaporación de una parte de la riqueza de muchos peruanos: "La obligación de pagar a los tenedores de billetes y de hacer honor a la firma del Estado era indiscutible; y la forma y manera de hacerlo en equidad y justicia constituía la solución del problema. El ministro [Aspíllaga] se pronunció por arrojar las existencias de ese papel al montón de deudas del Estado que habían caído en el derrumbe general o crac nacional" (Rodríguez y Dancuart, 1902-1926, t. XIX, p. 1617). Sin embargo, le enervaba también el agio de las elites siempre prestas a esquilmar al Estado, pagando sus tributos con esa moneda depreciada. La divisa de este grupo era según él: "iVivir siempre de la sangre del Estado y del pensionista!" (Rodríguez, 1887, p. 13). Rodríguez sostenía que el Estado tenía una responsabilidad moral con los billetes frente a la población y criticó las disposiciones del ministro de Hacienda, Antero Aspíllaga, de rehusar su admisión en las ventanillas del fisco, limitando su entrada en las aduanas con el artificio de crear un sobrecargo de 5\% sobre los derechos de importación, pagadero en dichos billetes. De hecho, Rodríguez propuso hacer del impuesto al tabaco el soporte económico para ir recogiendo los billetes y canjearlos por vales del Estado, que se amortizarían ulteriormente cuando el estanco del tabaco cobrara mayor solidez (Rodríguez, 1887, pp. 15 y ss.; véase también Rodríguez y Dancuart, 1902-1926, tt. XVIII y XIX).

La defensa de los derechos civiles y económicos del individuo frente a la arbitrariedad y el abuso del Estado, así como su crítica a la actitud parasitaria de la elite económica, vampirizando al presupuesto público, fueron en esta etapa de su vida una característica de su pensamiento, al 
que podríamos considerar por entonces inscrito en la vertiente del liberalismo. Para que las relaciones entre los ciudadanos y el Estado discurriesen con armonía y estabilidad debía conformarse una economía pública. Esta fue una especie de obsesión de Rodríguez desde su primera publicación, como la de toda la primera generación de economistas peruanos con la que interactuó, entre quienes podríamos nombrar a José Payán, Pedro Emilio Dancuart, Alejandro Garland, Luis Esteves, José Manuel Osores y Luis Larrañaga.

La experiencia agridulce del guano sembró en ellos la idea de que mientras dicha esfera económica no se formase, la nación viviría en un caos económico y político, puesto que la necesidad de rentas de los gobiernos, sin un mecanismo regular que las proveyese ordenadamente, pondría en permanente zozobra la economía de los particulares, quienes, de esta manera, tampoco podrían aprovechar los recursos de la naturaleza y las combinaciones del comercio. De esta suerte, la población sufriría el azote de gobiernos que, como los titanes de los mitos griegos, se alimentaban devorando a sus hijos (Larrañaga y Loyola, 1888, p. 23). En semejante escenario los hombres más avisados aprenderían que lo más lucrativo sería prenderse como ventosas de la cabeza y las extremidades del titán, para absorber algo de lo que este tomaba del cuerpo social.

La constitución de una economía pública pasaba por la creación de lo que Rodríguez consideraba un esquema fiscal saludable, basado en el impuesto. Durante la era del guano, entre 1845 y 1880, los gobiernos peruanos, según Rodríguez, habían practicado la política del "empréstito sin impuesto". Vale decir que sobre la base del dinero recibido de los consignatarios encargados de la extracción y venta del guano (oportunamente declarado un estanco, o monopolio público), los gobiernos contrataron préstamos en el extranjero que habrían de pagarse con las ventas futuras de guano y, optimistamente, con los retornos de la inversión que se haría con el dinero de los préstamos. Presionados por los pedidos de los congresistas, que querían acabar con los "rezagos del coloniaje", los impuestos que habían dejado los españoles, tales como las alcabalas, el diezmo agrario y minero, y el tributo indígena y de castas, fueron abolidos, sin que se creasen en su lugar impuestos "modernos" que cubriesen el vacío que dichas supresiones dejaban en las entradas del fisco.

Gran parte de los préstamos se consumió en gasto corriente y corrupción de los funcionarios; lo destinado a la inversión fue menos de la mitad; los destinos de la inversión, aunque interesantes tecnológica y geográficamente, como los ferrocarriles, fueron en lo económico una operación ruinosa. Después de diez años de iniciados los trabajos ferroviarios, su retorno anual montaba aproximadamente $0.5 \%$ de la cantidad invertida, cuando la deuda contratada debía pagar un servicio de $6 \%$ por año (Miller, 2011). 
La guerra del salitre desnudó súbitamente la precariedad de semejante esquema fiscal y mostró a los peruanos la plaga de lo que Rodríguez llamó "el empirismo" en el manejo de las finanzas públicas. La ciencia de las finanzas enseñaba, de acuerdo con Rodríguez (1895), que el empréstito sólo debía destinarse a gastos extraordinarios, como la construcción de infraestructura destinada al aumento de la producción y el comercio, mientras que para el gasto ordinario debía montarse un esquema basado en el impuesto. En la implantación de dicho esquema, al que genéricamente llamó la "reforma tributaria", basaba él el éxito o el fracaso de la república.

La primera generación de economistas peruanos surgió al calor de este grave problema que comprometía la viabilidad de la nación. La población asociaba los impuestos con las injustas cargas del "coloniaje" y creyó que la independencia debía implicar un régimen de alivio fiscal. Lejos de despertar a los peruanos de dicha fantasía, el fenómeno del guano la hizo posible, a costa de trastornar el sistema fiscal. Perdidas las rentas del guano y del salitre en la guerra contra los chilenos, la tarea de montar un nuevo esquema fiscal se alzó como una empresa urgente, volviendo tributaristas o "financistas", como entonces se decía, a los primeros economistas.

En materia fiscal, Rodríguez defendió un liberalismo clásico: debían implantarse impuestos livianos, pero universales y proporcionales a la riqueza de las personas. Entre 1886 y 1895 el país fue gobernado por el Partido Constitucional de Andrés Cáceres; primero bajo la presidencia del mismo general Cáceres (1886-1890) y después bajo la del general Remigio Morales Bermúdez (1890-1894); luego, volvió nuevamente Cáceres, pero fue derrocado por una revolución en 1895 al mando de Nicolás de Piérola. Bajo el gobierno de Morales Bermúdez, José Rodríguez, por entonces en la edad de la treintena, fue nombrado jefe de la sección de Aduanas y Estadística Comercial en el Ministerio de Hacienda y Comercio. Se trataba de un puesto delicado y de confianza puesto que en dicha coyuntura las aduanas constituían el principal soporte de los ingresos fiscales.

Rodríguez (1894) criticó las tarifas de aduana de la década de 1890 por excesivas: "son las más altas de todas las secciones de América del Sur" (p. 16). Implicaban un proteccionismo ciego y torpe de la industria nacional y privaban al gobierno de mayores ingresos, "pues en la ciencia financiera es ya un axioma que los impuestos elevados producen la disminución de la renta pública" (Rodríguez, 1894, p. 17). Había casi desaparecido la posibilidad de constituir nuevos estancos semejantes a los del guano y el salitre, esto por la falta de productos propicios para ello, cuanto por el descrédito que ese mecanismo fiscal tenía ahora entre la opinión pública. Pactar nuevos empréstitos era prácticamente imposible puesto que el país había entrado en cesación de pagos de su deuda externa desde 1876. De 
manera que el gobierno debía vivir ahora de los impuestos de sus ciudadanos, haciendo de la flaqueza una virtud.

En este giro drástico de la historia económica del país, Rodríguez (1895) escribió: "Propagar las ideas económicas es promover la prosperidad de una Nación" (p. III), revelando el optimismo positivista de la época, en que se creía que el problema de los países latinoamericanos había sido "el empirismo" en materia de gobierno y administración, es decir, la ignorancia de las leyes de la economía. El libro estaba dedicado a José Payán, financista cubano, por entonces gerente del Banco del Callao, el único que había logrado sobrevivir de los fundados antes de la guerra con Chile, a quien llama "obrero ilustrado é infatigable en la reconstitución económica de mi Patria” (p. II). Poco después, Payán se convertiría en gerente del Banco del Perú y Londres y dirigió el programa de traslado de la moneda peruana del patrón plata al patrón oro en 1897 (Camprubí, 1967). ${ }^{7}$ Rodríguez compartió la idea de la conveniencia de este traslado ante la actitud opositora de la mayor parte de la clase exportadora, que sacaba partido de vender en el exterior a cambio de libras esterlinas, pagando sus costos internos con monedas de plata devaluada. Incluso, a pedido de la Sociedad Nacional de Industrias, elaboró un informe acerca del impacto y conveniencia que tendría el cambio al patrón oro de la moneda peruana, en el que se manifestó a favor de él (Rodríguez, 1896).

Rodríguez (1895) combinó la difusión de las ideas económicas de los autores clásicos Smith, Say, Malthus, Ricardo, Mill y algunos otros menos destacados en la historia del pensamiento económico, como el español Flores Estrada y los franceses e italianos Bastiat, Molinari y Rossi, acerca del valor, la renta de la tierra, la riqueza y el pauperismo, el consumo y la moneda, con una historia del sistema tributario peruano desde la independencia hasta la guerra del salitre, en la que hace hincapié en las aduanas, cuya administración tenía en ese momento a su cargo. Su obra presentó a la reforma fiscal como la clave de la redención de Perú. Los elementos de dicha reforma eran para él: el respeto al presupuesto como un documento clave para definir el ámbito de la economía pública; el cuidado para que este no tuviese déficit, puesto que su aparición y crecimiento iba minando la confianza en el crédito público, y la concentración del ramo de ingresos en impuestos ajustados a los principios del liberalismo: previsibilidad, proporcionalidad, oportunidad y economía en la recaudación.

${ }^{7}$ José Payán y de Reyna (La Habana, 1844-Nueva York, 1919), inmigrante cubano llegado a Perú durante la década de 1870 . Dotado de una gran cultura económica y financiera $-y$ figura muy influyente en los debates monetarios durante la posguerra con Chile-, diseñó la adopción del patrón oro por Perú en 1897. 
La revolución de 1895 provocó el fin del gobierno cacerista y también del empleo de Rodríguez en la administración pública, que había durado casi diez años. Sobrevinieron para él años turbulentos en los que se enroló en un intento del cacerismo para retomar el poder mediante una insurrección armada. En 1898 lo encontramos en el departamento de La Libertad como delegado del norte al frente de una sublevación contra el gobierno de Piérola. Dispersados sus hombres en Facalá, huyó hacia el puerto ecuatoriano de Guayaquil. De ahí volvió poco después en una balandra de pescadores cargado de armas y refuerzos. Estuvo perdido 27 días, escondiéndose de la fragata Constitución, enviada por el gobierno peruano para interceptarlo. Finalmente logró desembarcar en una playa próxima a Pacasmayo, donde trabó combate contra las fuerzas del capitán Cox, quien al resultar herido, se retiró dejándole el campo libre. Al año siguiente, el presidente Piérola entregó el poder a López de Romaña; Rodríguez, siguiendo instrucciones de Cáceres, dio término a su rebelión, entregando sus armas al gobierno (Rávago, 28 de octubre de 1936).

A la espera de que el partido de Cáceres volviese al poder, lo que nunca llegó a ocurrir hasta la muerte de este caudillo y la extinción del partido en 1923, Rodríguez retomó sus actividades editoriales, siempre en la especialidad de las finanzas públicas. Entre 1900 y 1907 sacó a luz La Gaceta Comercial, un semanario de noticias vinculadas al comercio y las finanzas, donde quiso "servir intereses netamente mercantiles con frecuencia lesionados por el criterio fiscalista" (J. M. Rodríguez, El Economista Peruano, núm. 1, 1909, p. 1). Por esos años publicó en Lima el libro El nuevo sistema 0 reforma tributaria aplicable al mundo (1905), dedicado al entonces presidente de la república, José Pardo Barreda. ${ }^{8}$ En 1904 había recuperado su puesto de director de Aduanas, que no logró mantener mucho tiempo, por lo que en 1907 se trasladó a Buenos Aires, donde "un grupo de capitalistas" lo requirió para fundar en la capital argentina la compañía de seguros La Dotal, volcada a la mujer, donde se le aseguraba contra los riesgos de la orfandad, la viudez y el matrimonio (otorgándole en este caso una dote) (El Economista Peruano, 1909, p. 1).

En julio de 1907 salió de Buenos Aires de regreso a Lima. No sabemos exactamente cuándo desembarcó en esta ciudad, pero debió ser poco antes de la aparición de la revista El Economista Peruano, en marzo de 1909, fundada y dirigida por él "bajo los auspicios de la Banca y el Comercio de Lima" (véase cuadro 1). La revista llevaba como subtítulo Revista Mensual de Economía Política, Finanzas y Estadística y declaraba aspirar a convertirse en el órgano de un instituto del mismo nombre. Hasta el final de sus días persistió en el propósito de crear una entidad de este tipo; en 1935 lanzó

\footnotetext{
${ }^{8}$ No he podido hallar este libro en ninguna biblioteca.
} 


\section{CUADRO 1. LISTA DE AUSPICIADORES FUNDADORES DE LA REVISTA EL ECONOMISTA PERUANO, 1909}

Auspiciador

Banco del Perú y Londres

Banco Alemán Trasatlántico

Graham Rowe y Cía.

W. R. Grace y Cía.

Peruvian Corporation Limited

Empresas Eléctricas Asociadas

E. y W. Hardt

Milne y Cía.

Cerro de Pasco Mining Company

Juan V. Peral e hijo

E. Ayulo y Cía.

Brahm y Cía.

C. Weiss y Cía.

Societá por la Expotasione é per

l'Industria Italo-Americana

La Sud-América

Compañía Internacional del Perú

Compañía de Seguros Rímac

Compañía de Seguros Italia

La Dotal

Caloma Rehder y Cía.

Compañía Salinera Nacional

Nosiglie hermanos

Juan de Aliaga

J. H. Schmitt et Fils

Maisson Roddy

Aspíllaga hermanos

J. Hochkoppler e hijo

J. W. Bayley y Cía.

E. E. Marshalt

George Magot

Compañía de Seguros La Nacional

Compañía de Seguros Perú

Compañía de Seguros La Popular
Giro

Financiero

Financiero

Casa importadora y exportadora

Casa importadora y exportadora

Administradora de los ferrocarriles

Administradora de ferrocarriles urbanos

Casa importadora y exportadora

Empresa molinera

Empresa minera

Empresa molinera

Casa exportadora y comisionista

Casa importadora y exportadora

Casa importadora y exportadora

s. d.

Compañía de seguros

Compañía de seguros

Compañía de seguros

Compañía de seguros

Compañía de seguros y de previsión de dotes matrimoniales y pensiones para la vejez

Casa importadora

Administradora del estanco de la sal

Casa importadora

Casa importadora y comisionista

Casa importadora

Sastrería

Empresa agrícola azucarera de exportación

Fábrica de muebles

Importador de vinos y licores

Sin especificación

Sin especificación

Compañía de seguros

Compañía de seguros

Compañía de seguros 
Auspiciador

La Colectora

Empresa Agrícola de Palpa

Ingenio Central de Cartavio

Sociedad Agrícola Casa Grande

Sindicato de Potaza

Pow Lung y Cía.

Yec Fung Yuen y Cía.

Kuong Chong y Cía.

Ta Heng y Cía.

Pow Sang Fong y Cía.

Marioka y Cía.

Hop On Wing y Cía.

Aseng y Cía.

Wing On Chong y Cía.

Pow On y Cía.

Wang Fong y Cía.

C. Masson
Giro

Empresa arrendadora de inmuebles

También administraba el ferrocarril y muelle de Chancay

Empresa refinadora de azúcar

Empresa agrícola azucarera de exportación

Almacén de abarrotes y mercaderías chinas Importadora de artículos de China

Abarrotes del país y sederías de China

Almacén de sedas, casimires y lanas importadas

Almacén de abarrotes y mercaderías chinas s. d.

Casa importadora de artículos

Sin especificación

Sin especificación

Sin especificación

Almacén de abarrotes de productos chinos y del país

Sastre

Fuente: El Economista Peruano (1909, p. 12).

la idea de un Centro Económico Latino Americano (El Economista Peruano, septiembre 1938). Durante su periodo congresal, más precisamente en 1920, sacó a luz un folleto titulado Supresión del impuesto. ${ }^{9}$ Inspirándose en el planteamiento de la contribución única de las revoluciones europeas del primer liberalismo, Rodríguez propuso la abolición de los impuestos y su reemplazo por el pago de una cuota de "cooperativa social", iniciativa sufragada por todas las personas entre 21 y 80 años de edad, o su representante, de acuerdo a una escala que contemplaba cinco categorías de riqueza (Reinaga, 1969, p. 68).

${ }^{9}$ No hemos podido encontrar este folleto. Podría referirse a la supresión de algún impuesto específico, como los que afectaban el consumo de tabaco, fósforos, sal, alcoholes, etcétera. 


\section{Revista El Economista Peruano}

La revista El Economista Peruano sería la empresa de mayor aliento de nuestro personaje, puesto que la dirigió a lo largo de 26 años, hasta meses antes de su fallecimiento. En 1935, Rodríguez declaró "que dedica buena parte de su tiempo a esta publicación, exclusivamente de propaganda de la sana doctrina económica" (El Economista Peruano, núms. 26-27 [segunda era], 1935). Rodríguez escribía la mayor parte del contenido. De ordinario era el autor del artículo de entrada, que solía versar sobre la coyuntura económica del país y del mundo, y de un artículo adicional en el que exhibía sus dotes didácticas en torno a distintos temas de la ciencia económica, entre los que privilegió los concernientes a la economía laboral y fiscal. Se añadían artículos de otros colaboradores, algunos de los cuales enviaban reseñas sobre la producción agraria o minera en alguna región del país o informaban sobre los avances de las comunicaciones y el transporte. Se reproducían algunas leyes o disposiciones en materia comercial y tributaria y aparecían también informes económicos de otros países latinoamericanos, entre los cuales el corresponsal más constante fue Juan Ifernet, que reportaba acerca de la situación argentina. Ocasionalmente se reproducían, además, artículos de revistas españolas o mexicanas, acerca de temas vinculados a la economía europea o mundial, por ejemplo el experimento del fascismo italiano.

La revista no varió su diseño a lo largo de sus tres décadas de vida: un formato tamaño folio o "en cuarto" con doce páginas a dos columnas y paginación continua. Traía publicidad de los auspiciadores (casi todos los bancos y compañías de seguros de Lima, junto a varios establecimientos de comercio dedicados a lo que entonces se llamaba "el alto comercio": la importación y exportación), aunque esta nunca ocupó una porción importante de la revista. La contratapa traía la lista de los auspiciadores (véase cuadro 1). Rodríguez tuvo la habilidad necesaria para mantener su cuerpo de auspiciadores durante el cuarto de siglo que dirigió la publicación. La periodicidad fue mensual entre 1909 y 1930, aunque en este último año tuvo varios retrasos, convirtiéndose en bimestral ocasionalmente. Igual, publicó unos 240 números en esta primera etapa, que se cerró en junio de 1930. Este fue el año en que la crisis mundial impactó en Perú, quebrando varias casas comerciales y el Banco del Perú y Londres, institución con la mayor red de oficinas en el país (véanse Drinot y Contreras, 2014; Thorp y Londoño, 1988). Seguramente los problemas económicos de los auspiciadores determinaron la interrupción de la revista.

Una segunda etapa corrió entre octubre de 1932 y abril de 1936, en que la revista inició una nueva numeración y añadió la leyenda "segunda era”. La dirección se mantenía en manos de José Manuel Rodríguez, aun- 
que con una activa colaboración de sus hijos, Carlos Norberto Rodríguez Montoya y José Manuel Rodríguez Montoya. ${ }^{10}$ La suspensión de la revista después de abril de 1936 probablemente tuvo que ver con la salud del fundador, quien falleció en el mes de septiembre del mismo año, como ya habíamos dicho. En septiembre de 1938 comenzó una tercera era, bajo la dirección de José Manuel Rodríguez Montoya y Eduardo Rávago, figurando Carlos Rodríguez Montoya como secretario. Aparentemente el último número de la publicación apareció en diciembre de $1940 .{ }^{11}$

En 1912 Rodríguez fue convocado por el Ministerio de Hacienda para retomar la publicación de los Anales de la Hacienda Pública del Perú, que había iniciado Pedro Emilio Dancuart, otro financista peruano, en 1902. Bajo la dirección de Dancuart se publicaron diez volúmenes que cubrieron el periodo corrido entre la independencia y la crisis fiscal de los años de 1870 (asimismo, el primer tomo incluyó material sobre el periodo virreinal). Rodríguez publicó otros catorce tomos dedicados al periodo corrido entre 1876 y 1895 (Rodríguez y Dancuart, 1902-1926). Los Anales incluían un recuento cronológico de los principales hechos, sobre todo fiscales y legislativos, en materia económica, que Rodríguez no dejó de aderezar con comentarios acerca de la calidad u oportunidad de las medidas, junto con un cuerpo de documentos (leyes, memorias ministeriales, presupuestos nacionales y departamentales, etc.), que llenaba la mayor parte de cada volumen. Si sumamos los catorce volúmenes de los Anales con la cantidad de páginas escrita por Rodríguez en la revista El Economista Peruano (que publicó unas 3000 páginas entre 1909-1936, de las que no menos de la mitad debió corresponder a su pluma) además de sus libros y otros artículos publicados en revistas como El Mercurio Peruano, dirigida por Víctor Andrés Belaunde, no cabe duda que debió ser el economista más prolífico de la historia de Perú.

En 1919, con poco más de 60 años a cuestas, Rodríguez fue elegido diputado por la provincia de Otuzco, incorporándose a las comisiones de Hacienda y Presupuesto del Congreso de la República. Llegó a desempeñar la segunda vicepresidencia de la Cámara de Diputados (Benvenutto, 1923, p. 235). Fue elegido dentro del bloque auspiciado por Augusto Leguía, quien, aunque había ganado las elecciones presidenciales, unas semanas antes del cambio de mando (exactamente el 4 de julio de 1919) organizó un golpe de Estado que derrocó al presidente Pardo, a fin de asegurarse una mayoría en el Congreso. Rodríguez fue parte de los

\footnotetext{
${ }^{10}$ Ambos habían estudiado derecho en San Marcos en la primera o segunda década del siglo XX. José Rodríguez Montoya presentó en 1916 una tesis acerca del derecho de avería.

${ }^{11}$ Una colección casi completa de la revista puede verse en la Biblioteca Nacional del Perú. Asimismo, la biblioteca de la Universidad de San Marcos cuenta también con una colección.
} 
congresistas que acusaron al ex presidente Pardo por infracciones legales en materia fiscal (Benvenutto, 1923, pp. 235-236). Curiosamente, era el mismo hombre al que catorce años atrás había dedicado su libro sobre el nuevo modelo tributario.

En 1924, al concluir su periodo parlamentario, Rodríguez se aventuró a fundar un Partido Nacional Laborista. El año anterior había muerto Cáceres y el Partido Constitucional -en el que Rodríguez militó desde la década de 1880-, desapareció o estaba en vías de ello. La nueva organización estaba inspirada, según deja ver su revista, en el fascismo italiano. A su criterio, este movimiento parecía resolver las contradicciones que surgían entre el capital y el trabajo que tanta polémica causaron en el mundo de inicios del siglo XX. En las elecciones de 1931, el Partido Laborista, junto con otras agrupaciones, presentó la candidatura de Arturo Osores, otro viejo militante del Partido Constitucional, a la presidencia de la república. ${ }^{12}$ Los laboristas pensaban que un deber del Estado era defender el trabajo de los ciudadanos, haciendo respetar las leyes que protegían al trabajador de los abusos del capital, así como defendiendo sus empleos mediante el artificio del proteccionismo aduanero (El Economista Peruano, 1938). Tras la muerte de Rodríguez y la derrota de los países del eje en la segunda guerra mundial, el partido desapareció de la actividad política peruana.

\section{El LIBERALISMO NACIONALISTA}

La trayectoria del pensamiento de Rodríguez a lo largo de casi medio siglo de la historia de Perú resulta particularmente interesante. Comenzó proclamando ideas liberales que defendían al ciudadano y las empresas civiles del acoso fiscal del Estado, que nos recuerdan, en cierta forma, a los fisiócratas franceses del siglo XIX cuando protestaban contra la "politaxia". El terreno fiscal fue, ciertamente, uno de los más espinosos en la era de la posindependencia en Perú. Rodríguez reseñó la batalla que significaron los intentos, casi siempre infructuosos, de introducir impuestos modernos en Perú desde 1865, como el del timbre y otros que gravasen la propiedad territorial y los ingresos derivados del trabajo y el comercio (Rodríguez, 1895, pp. 255-279).

En la introducción de su libro de 1895, Estudios económico financieros, Rodríguez hizo un bosquejo de las líneas maestras de la historia económica de Perú, que durante el siglo Xx se convertirían en la versión más aceptada de dicha historia. De acuerdo con este guion, que podía aplicarse con pocas variantes a cualquier otro país hispanoamericano, cuando llegaron

${ }^{12}$ Osores quedó en cuarto lugar, consiguiendo sólo 6.5\% de los sufragios. 
los conquistadores españoles el pueblo peruano "era una blanda masa susceptible de recibir cualquiera forma de Gobierno y cualquiera sistema de impuestos: sólo necesitaba un modelador hábil, capaz de imprimirle una estructura..." (Rodríguez, 1895, p. IV). La colonización española se convirtió así en el elemento fundador del marco institucional del país. Desafortunadamente, los españoles no implantaron buenas instituciones económicas ni sanos principios financieros. Aplicaron un régimen de monopolio en el comercio y desalentaron el desarrollo de industrias competitivas con las de la península, afanándose sobre todo en la extracción de metales preciosos. Esto no promovió la innovación ni el adelantamiento técnico, ni el despliegue de nuevas industrias. Los colonos españoles también apartaron a los nativos de las tareas de gobierno, salvo en las tareas de caporales, y en el plano fiscal introdujeron un sistema tributario abusivo "sin orden ni plan en la distribución" (Rodríguez, 1895, p. VI).

La iniquidad de dicho esquema tributario fue el resorte que impulsó la independencia. Mas una vez emancipados -cuando tocaba echar mano a la tarea de diseñar un sistema tributario moderno y coherente con los principios de la libertad- la riqueza del guano y del salitre desvió al país de dicho rumbo, conduciéndolo, por el contrario, al de la corruptela, el derroche y el endeudamiento ruinoso (Rodríguez, 1895, pp. VI-VII). Dos grandes baches habrían apartado así a Perú de una evolución económica saludable: la colonización española, que no trajo las ideas más avanzadas en materia económica y financiera, y, paradójicamente, la riqueza de los fertilizantes, que implicaron una bonanza pasajera y en el largo plazo esterilizante.

Siguiendo las líneas del liberalismo, Rodríguez reclamaba el respeto al presupuesto fiscal y el establecimiento de un sistema impositivo "científico" basado antes en los impuestos directos que en los indirectos. Los impuestos indirectos propiciaban el desorden, la multiplicidad fiscal y acababan recayendo sobre quienes no debía (Rodríguez, 1895, p. 130). Entre los impuestos directos recomendaba la introducción del impuesto territorial y del impuesto proporcional a la renta y el capital mobiliario $(E l$ Economista Peruano, núm. 29 [segunda era], 1935). Ambos eran de difícil aplicación en Perú durante el primer tercio del siglo Xx. La mayor parte de la propiedad territorial no estaba titulada y gruesa parte de las rentas tampoco estaban formalizadas en documentos o cuentas fiscalizables, por lo que dichos impuestos apenas comenzaron a introducirse por entonces. Debido al régimen de descentralización fiscal vigente desde 1887, los impuestos de tipo territorial yacían en manos de los gobiernos locales (las municipalidades), razón por la que el Estado central no cobró interés en su fortalecimiento. Mientras dichos impuestos no estuviesen consolidados, Rodríguez aceptaba que el sistema fiscal había de resignarse a convivir con 
los impuestos indirectos, como los de las aduanas, pero sin perder nunca de vista su poca conveniencia desde el punto de vista de la proporcionalidad y la neutralidad fiscales (El Economista Peruano, núms. 32-33 [segunda era], 1935; Rodríguez, 1895, pp. 129 y ss.).

Un cuarto de siglo atrás, observando el mundo desde la era de la "paz armada" previa a la primera guerra mundial, Rodríguez había concebido los sistemas fiscales y los ejércitos como los elementos centrales de una carrera darwiniana por la supervivencia de los Estados. Únicamente los países con economías fuertes y sistemas fiscales eficaces podían permitirse mantener ejércitos permanentes. El estado de "guerra inminente" o "paz armada" en que vivía el mundo iba a resultar insostenible para muchas naciones (El Economista Peruano, núm. 1, 1909). Ello no sólo ocurría en Europa, sino también en Sudamérica, donde Perú, por ejemplo, vivía una situación tensa con sus vecinos, especialmente con Chile y Ecuador, con quienes mantenía diferendos fronterizos que en los siglos XIX y XX desembocaron en guerras abiertas y cruentas. El establecimiento de una fiscalidad adecuada resultaba así una condición para la preservación de la soberanía nacional.

Respecto del comercio exterior, Rodríguez defendió la postura del "proteccionismo", al que describió como un punto medio entre los extremos del mercantilismo o sistema "prohibitivo", y el libre comercio, que pide la supresión de las aduanas. Consideraba al proteccionismo comercial, en todo caso, como una fase temporal, propia para las economías de desarrollo intermedio, que al fin permitiría arribar al libre cambio:

El libre cambio ó sea el ejercicio del derecho que el hombre tiene para negociar del modo que mejor le agrade, sin otra ley que la que le dicte su interés, comprando y vendiendo á quien, cómo y dónde quiera los frutos de su trabajo, dadas las condiciones actuales de las diversas naciones que pueblan el globo y que merced á los inventos modernos están en continua é inmediata comunicación, no pasaría de ser una bellísima teoría, en tanto que llegue el día de la paz perpetua y universal mediante un alto grado de progreso y civilización en todas y cada una de ellas. A su vez, el proteccionismo en su mayor grado de perfección sería incompleto, si, como corona de sus esfuerzos, no tuviera por fin único, proclamar el imperio de la libertad comercial en todo el mundo (Rodríguez, 1895, pp. 413-114).

Una postura que podríamos llamar de nacionalismo desarrollista atemperó el liberalismo doctrinal de Rodríguez, como el de otros autores que escribieron en la revista El Economista Peruano. ${ }^{13}$ En el terreno de lo abstracto, él se definía como un liberal; por ejemplo en 1910, respecto

${ }^{13}$ Entre ellos, por ejemplo, Ricardo Tizón y Bueno, que era un ingeniero, algo más joven. 
de un debate sostenido en torno de la conveniencia de la rebaja del impuesto de aduana que pagaba la harina de trigo importada (de cuatro a tres centavos por kilo), a fin de abaratar el precio del pan, manifestó que en un principio "alistamos nuestros bagajes para ir a formar como simple opinión ciudadana en las filas de los librecambistas, sirviendo así al programa del 'Economista Peruano' y nuestras propias convicciones...” (El Economista Peruano, núm. 12, 1910). Pero en el campo de los casos específicos terminaba casi siempre oponiéndose a las rebajas de los derechos arancelarios para ponerse al lado de la industria nacional. En este episodio de la harina, por ejemplo, terminó señalando que la rebaja perjudicaría a la industria molinera nacional, volviendo a Perú "tributario del pan de los países extranjeros", además de dañar los intereses fiscales. Reconocía que la industria molinera había nacido precisamente al amparo del derecho diferencial que pagaba el trigo importado de la harina importada (1.25 soles contra cuatro soles por kilo, respectivamente), pero ya tenía carta de ciudadanía y contribuía al trabajo nacional. ${ }^{14}$

En sus Estudios económico financieros (1895), había manifestado ya que, desde el punto de vista del teórico, el hombre debía procurar el libre cambio, pero que desde el punto de vista práctico, el administrador o gobernante debía seguir un proteccionismo selectivo, cuidando de favorecer el trabajo y la producción nacionales. Citando al economista alemán Friedrich List, argumentaba que las ideas del libre cambio eran ideales y perfectas para un mundo ideal y perfecto; en el que todas las naciones fueran igualmente adelantadas en su industria y reinase la paz y la concordia entre ellas, pero que la economía política es una ciencia práctica que "debe tomar al mundo como está, como es, y enseñar de qué manera tal ó cual nación en circunstancias dadas, se eleva por la agricultura, por la industria y por el comercio al bienestar, á la civilización y al poder..." (Rodríguez, 1895, p. 409). En su folleto de 1894 propuso reemplazar el arancel peruano dominado por tarifas altas, de un nivel de 40 o 45\% de pago por las importaciones, por uno de tres niveles: de 10, 20 y 35\%, que deberían aplicarse, respectivamente, a la maquinaria e insumos que el país no producía, a los artículos manufacturados o de lujo cuya producción era escasa o nula y a los artículos que sí tenían producción corriente o que eran fáciles de desarrollar (Rodríguez, 1894, p. 18).

$\mathrm{Si}$ a las naciones con una industria consolidada les convenía un sistema de libre comercio, lo mismo ocurría con las naciones carentes de toda industria, que yaciesen en un estadio agrícola y pastoril; esta se ve obligada a abrazar el libre comercio. El proteccionismo, en cambio, era "propio de

${ }^{14}$ Pudiera ser, en algunos casos, que la dependencia económica de la revista respecto de los auspiciadores, volviera su posición poco independiente. 
pueblos que han avanzado algo en las conquistas del progreso y que, por lo mismo, tienen algo que amparar ó proteger" (Rodríguez, 1895, p. 416). En suma, de acuerdo con sus ideas, el libre cambio era el ideal a alcanzar; el proteccionismo un medio para llegar a dicha meta. En un discurso pronunciado en 1910 en la Cámara de Diputados respecto a la modificación de la tarifa de los derechos aduaneros (que eran relativamente altos en el Perú de entonces), se manifestó en el mismo sentido:

yo me permito aconsejar a la H. Cámara, que tan benévola es para todas las opiniones, que sea protectora para los cueros, el jabón, el arros [sic], los algodones, el azúcar, etc., y libre cambista con el papel, el trigo, harina, vinos, medicamentos, máquinas, etc., en una palabra, protectora, para lo que tiene la patria con facilidad; libre cambista para aquello que le falta y de que a menester, sin embargo, para el sostenimiento de la vida nacional (aplausos) (El Economista Peruano, núm. 15, 1910).

Respecto de los problemas para el progreso económico que habían enfrentado desde su independencia las naciones americanas, Rodríguez los sintetizó en dos: vialidad y población. Tales eran, al menos, los desafíos con que habían nacido: mala vialidad y escasa población. Los países del lado del Atlántico, casi los habían resuelto. Citó los casos de Estados Unidos, México, Brasil, Uruguay y Argentina, donde la inmigración aumentaba la población y renovaba las ideas. Pero las cosas habían sido más lentas en las demás naciones, las que "limitadas á un crecimiento vegetativo, continúan viviendo en el régimen de autoridad disfrazado con el ropaje de la República [...]” (El Economista Peruano, núm. 4, 1909). Sin embargo, era optimista en que la inminente apertura del canal de Panamá redimiría a estos países, facilitando que a ellos fluyese la inmigración. La vialidad debía resolver, así, los problemas de población (El Economista Peruano, núm. 39, 1912, pp. 478-479).

En materia de estructura social participaba de las ideas del darwinismo social, muy influyentes en su época. ${ }^{15}$ Pensaba que uno de los problemas de "población" de Perú era que dentro de un número de 4000000 de habitantes, aproximadamente 1000000 consistía en indígenas analfabetos, degradados y serviles. En la región de la costa "el cruzamiento de las razas" había mejorado el panorama, pero en la sierra la cuestión de la vialidad mantenía a una abultada población de indios en la ignorancia e inermes frente a los abusos del "funcionarismo". Este flagelo consistía en que los funcionarios despachados por el gobierno para la administración

\footnotetext{
${ }^{15}$ Sobre el darwinismo social en Perú, véase Palma (1897). Un argumento más bien contrario puede verse en Graña (1908). Como miradas académicas recientes para el conjunto de América Latina, véanse Stepan (1996) y Miranda y Vallejos (2005).
} 
de las poblaciones disponían del trabajo de los indios y de sus familias, imponiéndoles faenas, multas y confiscaciones en beneficio muchas veces personal. El funcionarismo conducía a que en los departamentos de Puno, Cuzco, Ayacucho y Junín los indios vivieran en una especie de "servidumbre voluntaria que encuentran mejor que la del obrero libre, quien no tiene amparo ante la voracidad del funcionarismo civil, político y eclesiástico" (El Economista Peruano, núm. 35, 1912, p. 415). Como solución proponía la conversión de las comunidades indígenas en cooperativas de crédito (El Economista Peruano, núm., 30, 1911, pp. 358 y ss.). ${ }^{16}$ Pero, sobre todo, esperaba que la inmigración europea, una vez abierto el canal panameño, renovaría la población en un sentido positivo, tal como había ocurrido ya en los países del lado Atlántico del continente. Este flujo, junto con las obras de vialidad consistentes en ferrocarriles, telégrafos y caminos de herradura, pondría al Perú en la senda del progreso (El Economista Peruano, núm. 39, 1912, pp. 478-479). ${ }^{17}$

En sus últimos años, en el decenio de 1930, Rodríguez radicalizó su nacionalismo económico. Mediante su observación de las leyes de la economía, se percató de que algunas de ellas no se verificaban en este lado del mundo. Esto sucedía, por ejemplo, con la "ley de la gravitación" de los precios de los bienes básicos. Estudiando las estadísticas de cómo, expresados en horas de trabajo de un jornalero, los precios de los alimentos, la ropa y la vivienda habían descendido en Inglaterra, Francia y otros países europeos a lo largo del siglo XIX, observó que "En los países incipientes, como los de Sudamérica, por ejemplo, los precios de venta en vez de seguir la ley general, han subido, [...]" (El Economista Peruano, núm, 5, 1909, p. 59). La tendencia declinante de los precios en las naciones avanzadas ocurría a raíz de las mejoras que se obtenían progresivamente en la productividad y el transporte, por razón de la competencia. En los países incipientes esto no sucedía porque escaseaba todo lo necesario para producir y vender los bienes: especialmente capitales y transporte, pero también por razón de haber seguido el sistema de "derechos protectores" en las aduanas, minando la competencia.

Reflexionando acerca de los problemas que enfrentaba el progreso económico de las naciones latinoamericanas, Rodríguez enfocó lo que llamó el "absentismo de los capitales". El fenómeno de la bonanza exportadora de materias primas en los inicios del siglo XX atraía capitales del

${ }^{16}$ Siguiendo las ideas del darwinismo social, añadía que entre las razas había diferencias de inteligencia y experiencia, por lo cual "Al blanco debe ser reservado el trabajo intelectual que exige la dirección, mientras que el indio se presta al trabajo manual o físico, por estar ya acostumbrado al clima y ser incapaz de trabajo intelectual".

${ }^{17}$ Sin embargo, quedada por resolver el problema de la vialidad en "el oriente" (la Amazonía), al que señalaba como "el gran problema del presente". 
exterior, pero que volvían a salir, aumentados con la ganancia, dejando para el país una apenas "leve huella" en la forma de algunos salarios y cierta circulación interior:

Y aun en las repúblicas donde más crece la población como Argentina, Brasil y Uruguay, la vida es cara y los salarios por lo general bajos; porque en estos países se produce en gran escala el fenómeno del absentismo y la salida de capitales que vienen de fuera en forma de moneda, atraídos por la perspectiva de beneficios, vuelven á salir aumentados en forma de mercaderías, sin dejar en el país explotado más que una leve huella, como salarios de la menor tasa posible y la circulación monetaria consiguiente á las diversas necesidades del negocio (El Economista Peruano, núm. 16, 1910, p. 181).

El fenómeno de las balanzas comerciales superavitarias, que caracterizó a las economías latinoamericanas durante la así llamada "era de las exportaciones", tenía severas implicaciones fiscales, puesto que como la parte más importante de los ingresos de los gobiernos provenía en esa época de los derechos de importación (Márquez, 2005), resultaba que estos ingresos no aumentaban conforme lo hacía la economía, puesto que el aumento de las exportaciones no era seguido de uno paralelo de las importaciones. Para Rodríguez era el "absentismo de los capitales" la causa de esta anomalía que los economistas llamaron más adelante el problema de las "economías bajo absorbentes" (Kindleberger, 1988). Los capitales que movían la economía de exportación provenían del exterior, lo que traía como consecuencia que sus retornos o ganancias no resultaban en mayor consumo en el país exportador, ya que podían ser simplemente retenidas por sus dueños en el exterior. Podía así ocurrir el extraño fenómeno, que se presentó en el Perú de las décadas de 1890 y 1910, de exportaciones al alza, junto con la decadencia de la recaudación de aduanas (Rodríguez, 1894, p. 6).

Se trataba, decía el autor, de una situación de "paradoja económica", consistente en que las actividades que principalmente aportaban a la riqueza nacional, como la agricultura y la minería, "al mismo tiempo concurren al empobrecimiento con los fuertes saldos positivos del comercio exterior que quedan en el extranjero; [...]" (El Economista Peruano, núm. 29 [segunda era], 1935, p. 286). Puesto que esta paradoja se presentaba de forma "impávida, irónica y permanente", proponía la intervención del Estado bajo la forma de un control de la salida de capitales. El saldo positivo de la balanza comercial que de ordinario resultaba durante las bonanzas exportadoras debía manejarse mediante un control de las divisas (El Economista Peruano, núm. 4 [segunda era], 1933). Elogió en este sentido la política alemana de "comercio exterior sin divisas sobre la base de un 
tráfico de compensación o de clearing de país a país", mediante el cual se evitaba la salida de los excedentes de capital (El Economista Peruano, núm. 33 [segunda era], 1936, p. 392). Eran los inicios de la crítica a la inversión extranjera directa, que posteriormente se generalizaría en América Latina, por la emigración de capitales que implicaba.

Tales ideas parecen ya muy apartadas del liberalismo y lo aproximaban en cambio a las ideas del nacional socialismo que Rodríguez parece haber mirado con atención en sus últimos años. ${ }^{18} \mathrm{El}$ economista peruano siempre miró con interés y simpatía los episodios de crecimiento económico e industrialización "gerschenkronianos" (logrados con un fuerte apoyo del Estado y con el añadido de una mística nacionalista e industrialista), como los de Japón, Italia y Alemania, seguramente porque vio en ellos historias que las naciones latinoamericanas podían imitar (Gootenberg, 2002).

En esa misma línea habría que destacar su manía de proponer bancos como una forma de resolver los problemas del atraso. En 1912 ya proponía el establecimiento de un Banco Agrícola que, por un lado, libre del agio del que los agricultores de departamentos como Ica, volcados a la producción vitivinícola y algodonera, eran víctimas por parte de sus habilitadores, y, por otro, fortaleciese a los empresarios agrarios que, una vez abierto el canal de Panamá, deberían enfrentar a empresarios de naciones mejor dotadas de recursos financieros (El Economista Peruano, núm. 36, 1912, p. 418). En 1935 propuso fundar otros dos bancos: uno de Crédito al Trabajo y otro de la Colonización, como una forma eficaz de impulsar el consumo (el primero de estos bancos daría crédito al trabajador hasta por $80 \%$ del monto de su salario y funcionaría como una tarjeta de crédito de hoy) y la roturación de tierras en la Amazonía (El Economista Peruano, núms. 3233 [segunda era], 1935). En su pensamiento, los bancos eran liberadores de la energía que habitaba en los agentes económicos y, en ocasiones, debían ser impulsados por el gobierno a fin de romper el oligopolio de los habilitadores nacionales y extranjeros que disminuían las ganancias de los agricultores y mineros.

\footnotetext{
${ }^{18}$ Desde la década de 1920 la revista El Economista Peruano publicó varios artículos referentes al experimento del fascismo italiano, generalmente reeditados de la prensa española. Después de la muerte de Rodríguez esta tendencia se acentuó, incluso, en la revista, publicando en un número de 1938 una foto a toda página de Hitler y Goebbls al final de un mitin político en Alemania.
} 


\section{REFLEXIÓN CONCLUSIVA}

José Manuel Rodríguez representó la combinación de liberalismo y nacionalismo que en general caracterizó el pensamiento económico peruano y latinoamericano en la transición del siglo XIX al XX (Jacobsen, 2002, 2007). Su lado liberal se vio alimentado por la experiencia frustrante del guano, en que los peruanos parecieron haber desaprovechado una oportunidad de progreso. Rodríguez sostuvo que fue el episodio del guano lo que desvió a Perú de la "saludable corriente" de "los librecambistas ingleses" (El Economista Peruano, núm. 41, 1912, p. 478). El abandono del impuesto como medio de sustento del tesoro público y el descuido en la confección del presupuesto y en su fiscalización prepararon el desastre de la guerra del salitre. Su lado nacionalista nació de la necesidad del país para lograr crecimiento económico después de la derrota, a fin de poder reconstruir las finanzas públicas y sostener una fuerza armada que garantice, sino la recuperación de las provincias cautivas de Tacna y Arica, al menos la mantención de la soberanía nacional. ${ }^{19}$

Su apuesta por el nacionalismo se volvió más clara a partir de 1910. Creía en el nacionalismo como una herramienta eficaz para el progreso económico de las naciones. Una de las tareas de los gobiernos debía ser la defensa de los intereses económicos nacionales. La revista El Economista Peruano declaraba como objetivo en su primer número de 1909 "defender y propagar los Intereses económicos del Perû" (cursivas del original. El Economista Peruano, núm. 1, 1909). La política nacionalista cobraba una especial relevancia en un país cuya especialización en el comercio mundial de la época reposaba en la minería y la agricultura de plantaciones. Pero Rodríguez la encaminaba sobre todo al tema de la balanza comercial, por ejemplo: "no [debería el gobierno] consentir que se importen mercaderías procedentes de naciones que no compran productos peruanos, y cuidar que la importación sea proporcional a la exportación con la tolerancia de 10\% a favor de aquella" (El Economista Peruano, núm. 39, segunda era, 1936, p. 1).

Otra característica de nuestro personaje fue su enfoque histórico. Siempre abordó los temas económicos desde una perspectiva de largo plazo y atento a las transformaciones ocurridas a través del tiempo, recogiendo la metodología de la Escuela Histórica Alemana. Gracias a ello dejó un

\footnotetext{
${ }^{19}$ Las provincias de Tacna y Arica estaban retenidas en manos de Chile desde 1880. De acuerdo con el Tratado de Ancón de 1883, que puso fin a la guerra del salitre, un plebiscito en ellas debía decidir si quedaban en manos de Perú o de Chile, pero para llevarlo a cabo, Perú debía empozar una garantía de 10000000 de pesos plata.
} 
compilado de estadísticas históricas nacionales muy valioso para las generaciones siguientes. ${ }^{20}$

Rodríguez fue parte de una generación de intelectuales positivistas que trataron de introducir y asentar las prácticas económicas republicanas, que ellos identificaron con las "modernas", sobre todo en el nivel de la economía pública: el respeto al presupuesto sin déficit y la obtención de los ingresos del Estado por la vía del impuesto, que propiciaba la responsabilidad fiscal. Abogó por los impuestos directos y por un proteccionismo práctico, en defensa de la producción nacional. Los dos principios económicos que el Partido Constitucional (en el que Rodríguez militó la mayor parte de su vida) enarboló a partir de 1910 llevaron la huella de sus ideas; dichos principios fueron: el presupuesto sin déficit y la protección a la producción nacional (El Economista Peruano, núm. 20, 1911, p. 312).

En el plano de la economía civil buscó una conciliación entre el capital y el trabajo, bajo cierta influencia del fascismo. Desembocó así en una corriente que podríamos llamar de "nacional-liberalismo", distinta al "nacional-socialismo" europeo, por la mayor debilidad del Estado en el caso peruano, pero que compartía con él la idea de que el Estado debía ser el gran árbitro entre las clases empresarial y trabajadora, al mismo tiempo que debía desplegar una política protectora de las empresas nacionales e impulsora del crecimiento económico.

No es fácil resumir los aportes de Rodríguez al pensamiento económico peruano, porque antes de él no hubo ninguna figura que pensase con cierta sistematicidad en los problemas económicos nacionales. ${ }^{21}$ En todo caso, fue el último en apoyar puntos que habían menudeado durante todo el siglo XIX, como la atracción de inmigrantes europeos, y a la vez el que introdujo nuevos temas, sobre los que abundaría la reflexión económica posterior, como un esquema de la historia económica nacional que encontraba en la colonización española y la experiencia del guano los dos grandes vectores que habrían distorsionado la evolución económica de Perú: la defensa de un esquema de comercio exterior semiabierto, en el que no dejase de protegerse a la producción nacional mediante un sistema de arancel escalonado, ni de velarse por los intereses fiscales, y la crítica a la inversión directa extranjera, que, al controlar los principales sectores de exportación, propiciaba la salida de los capitales, impidiendo que las exportaciones completasen un círculo benéfico para los intereses nacionales. Inició también el reclamo por una banca de fomento como una

\footnotetext{
${ }^{20}$ Shane Hunt, quien usó muchas de sus cifras, le llama "el infatigable Rodríguez" en uno de sus trabajos (Hunt, 2011).

${ }^{21}$ Gootenberg (1998) analiza a algunos autores que mostraron sus preocupaciones por el progreso de la economía nacional a través del apoyo a la agricultura, la inmigración europea, la industria nacional o la inversión en infraestructura de transporte.
} 
forma de abaratar el crédito a los industriales y fue un tenaz defensor de la necesidad de una reforma fiscal para conseguir una interacción fructífera entre la economía pública y la privada. Para un país que desde mediados del siglo de la independencia no halló una forma virtuosa de compensar la desaparición del tributo indígena, no cabe duda que se trató de un reclamo acertado.

Perú no es un país que se caracterice por el culto a sus pensadores económicos, pero sorprende de todos modos que una figura original, prolífica y activa como José Manuel Rodríguez haya sido olvidada después de su muerte. Una razón podría ser el desprestigio que sufrieron las ideas nacionalistas del tipo fascista tras la segunda guerra mundial. Como él había fundado el Partido Nacional Laborista y su revista había desplegado actitudes de simpatía con el fascismo italiano y el nazismo alemán pareció conveniente correr un tupido velo sobre su obra. Otra razón sería más bien social. A pesar de su talento y su laboriosidad Rodríguez era ajeno a la elite social, en un país donde la nobleza de cuna representaba un requisito importante para verse catapultado a la categoría de personaje ilustre. Logró ascender como funcionario público en mérito a su olfato político, su tesón y su talento, y logró sobrevivir económicamente en virtud de las alianzas que hizo con las empresas del "alto comercio" y las finanzas en coyunturas en que este experto tributarista podía resultarles útil. Gracias a ello pudo mantener a su familia y publicar una vasta obra, pero careció del ascendiente que proporciona pertenecer a la elite social o económica.

\section{LISTA DE REFERENCIAS}

ARRAmbide, V. (2013). Recuerdos de la Universidad de San Marcos antes de la guerra con Chile. En M. Maticorena (ed.), La Universidad de San Marcos de Lima. Documenta Histórica. Lima: Universidad Mayor de San Marcos.

Benvenutto, N. (1923). Parlamentarios del Perú contemporáneo, 1904-1923. Lima: Imprenta Malatesta-Rivas Berrío.

CAmprubí, C. (1967). José Payán y de Reyna (1844-1919). Su trayectoria peruana. Lima: P. L. Villanueva.

Drinot, P. y Contreras, C. (2014). The great depression in Peru. En P. Drinot y A. KNight (eds.), The Great Depression in Latin America (pp. 102-128). Durham/Londres: Duke University Press.

Gootenberg, P. (1998). Imaginar el desarrollo. Las ideas económicas en el Perú postcolonial. Lima: Instituto de Estudios Peruanos/Banco Central de Reserva del Perú.

GootenberG, P. (2002). ¿Hijos del Dr. Gerschenkron? El extraño caso de los conceptos de desarrollo tardíos en la historia económica latinoamericana. En C. CON- 
Treras y M. Glave (eds.), Estado y mercado en la historia del Perú. Lima: Pontificia Universidad Católica del Perú.

Graña, F. (1908). El problema de la población en el Perú. Inmigración y autogenia. Lima: Tipografía El Lucero.

Hunt, S. (2011). La formación de la economía peruana. Lima: Instituto de Estudios Peruanos/Banco Central de Reserva del Perú.

Jacobsen, N. (2002). Pensamiento económico y políticas económicas en el Perú, 18851899. En C. Contreras y M. Glave (eds.), Estado y mercado en la historia del Perú. Lima: Pontificia Universidad Católica del Perú.

Jacobsen, N. (2007). "Liberalismo tropical" ¿cómo explicar el auge de una doctrina económica europea en América Latina, 1780-1885? Historia Crítica, 34, 118-147.

Kindleberger, CH. (1988). Historia financiera de Europa (trad. A. Menduiña y J. Tugores). Barcelona: Crítica.

Larrañaga y Loyola, L. (1888). Apuntes sobre la situación económica del Perú. Lima: Bacigalupi.

Márquez, G. (2005). Aranceles a la importación y finanzas públicas: del porfiriato a la crisis de 1929. En L. Aboites y L. Jáuregui (coords.), Penuria sin fin. Historia de los impuestos en México, siglos XVIII-XX. México: Instituto de Investigaciones Dr. José María Luis Mora.

Milla, C. (ed.) (2004). Diccionario biográfico del Perú contemporáneo: siglo XX (2 vols.). Lima: Carlos Milla Batres.

Miller, R. (2011). Empresas británicas, economía y política en el Perú, 1850-1934. Lima: Instituto de Estudios Peruanos/Banco Central de Reserva del Perú.

Miranda, M. y Vallejos, G. (eds.) (2005). Darwinismo social y eugenesia en el mundo latino. Buenos Aires: Siglo XXI.

Morón, E. (1993). La experiencia de banca libre en el Perú: 1860-1879. Lima: Universidad del Pacífico.

Palma, C. (1897). El porvenir de las razas en el Perú. Lima: Imprenta Torre Aguirre.

Pradier-Foderé, P. (1876). Compendio del curso de economía política, de estadística y de ciencia de finanzas (traducción de Manuel Atanasio Fuentes). Lima: Imprenta del Estado.

RÁvago, E. (28 de octubre de 1936). A un mes de la muerte de Rodríguez. Nota necrológica, El Comercio.

Reinaga, C. A. (1969). Esbozo de una historia del pensamiento económico en el Perú. Cuzco: Garcilazo.

Rodríguez, J. M. (1887). El billete fiscal. Estudio sobre su conversión y amortización que presenta a la Cámara de Diputados J. M. Rodríguez, empleado de su Secretaría; dedicado especialmente a los honorables miembros de las Comisiones de Presupuesto y Hacienda. Lima: Imprenta de Torres Aguirre.

Rodríguez, J. M. (1890). Ricardo O’Donovan. Episodios de la guerra del Pacífico. Leyenda histórica. Trujillo: Imprenta de El Independiente. 
Rodríguez, J. M. (1894). Informe presentado al Sr. Ministro de Hacienda y Comercio por el Visitador de las aduanas de la república Sr D. José M. Rodríguez, Jefe del Ramo en el Ministerio de Hacienda. Junio de 1894. Lima: Librería e Imprenta y Encuadernación Gil.

RodRÍGUEZ, J. M. (1895). Estudios económicos financieros y ojeada sobre la Hacienda pública del Perú y la necesidad de su reforma. Lima: Librería, Encuadernación e Imprenta Gil.

RodRíguez, J. M. (1896). Informe acerca del impacto y conveniencia que tendría el cambio al patrón oro de la moneda peruana [Folleto], Sociedad Nacional de Industrias, Lima, Perú.

Rodríguez, J. M. (1905). El nuevo sistema o reforma tributaria aplicable al mundo. Lima: Autor.

Rodríguez, J. M. y Dancuart, P. E. (1902-1926). Anales de la Hacienda pública del Perú (tt. XVIII y XIX [1918]). Lima: Ministerio de Hacienda.

Roque, L., Paz Estensoro, V., Nogueira de Paula, L., Keller R., C., Portela, G., Charlier, E. D., Maldonado, S. y Romero, E. (comps.) (1945). El pensamiento económico latinoamericano. México: Fondo de Cultura Económica.

Stepan, N. L. (1996). The hour of eugenics. Race, gender and nation in Latin America. Ithaca: Cornell Univesity Press.

Tauro, A. (1966). Diccionario enciclopédico del Perú: ilustrado (3 vols.). Lima: Editorial Mejía Baca.

Thorp, R. y Londoño, C. (1988). El efecto de la Gran Depresión de 1929 en las economías de Perú y Colombia. En R. ThOrp (comp.), América Latina en los años treinta. El papel de la periferia en la crisis mundial (pp. 103-138). México: Fondo de Cultura Económica.

\section{OTRAS FUENTES}

\section{Hemerografia}

El Economista Peruano, 1909-1936, núms. 1-41 (primera era) y núms. 4-39 (segunda era). El Comercio, Lima, Perú. 